This item was submitted to Loughborough's Institutional Repository (https://dspace.lboro.ac.uk/) by the author and is made available under the following Creative Commons Licence conditions.

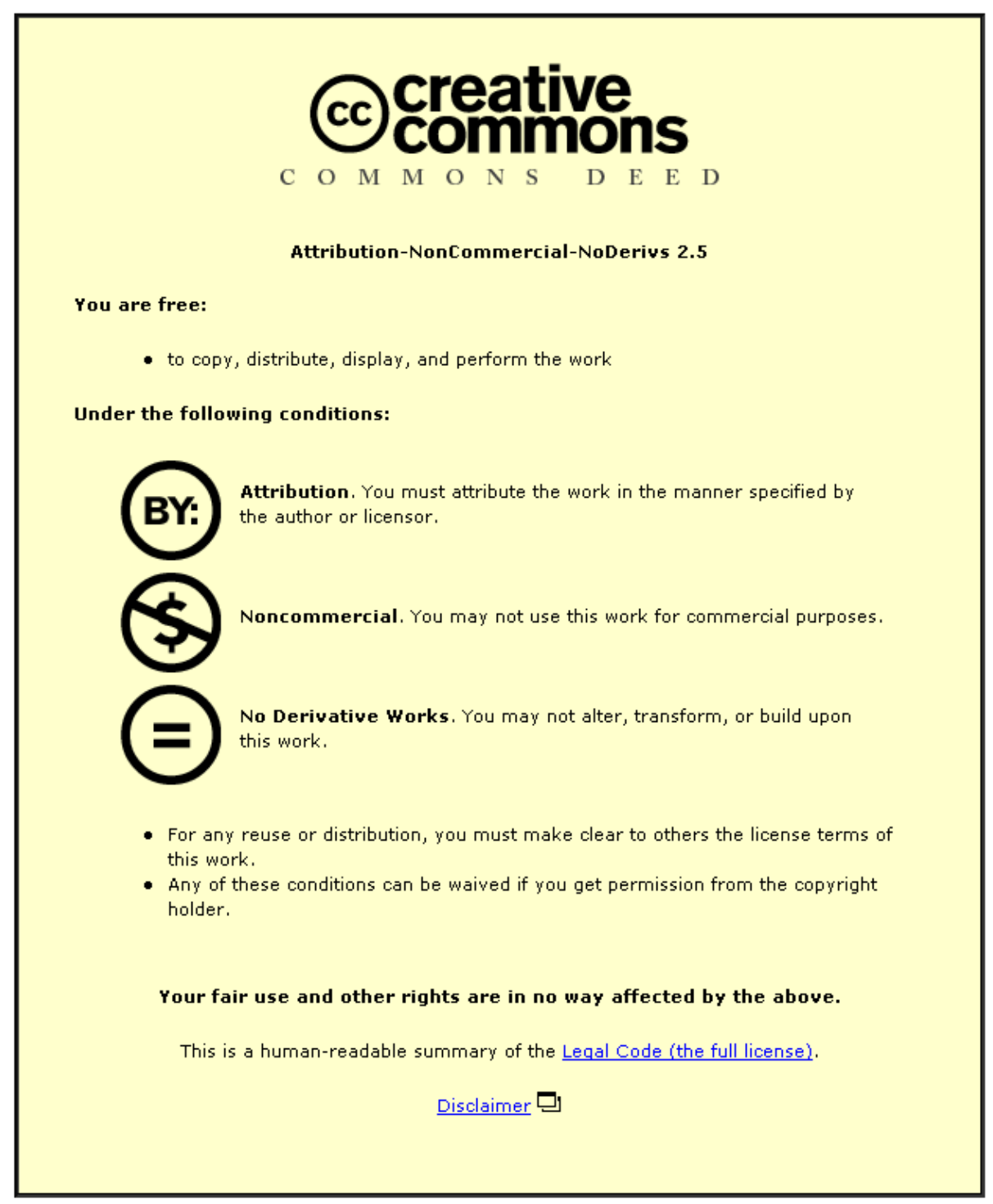

For the full text of this licence, please go to: http://creativecommons.org/licenses/by-nc-nd/2.5/ 


\title{
A Novel Bioreactor for Immobilized Phototrophs
}

\author{
Saskia Fermont and Gilbert Shama
}

Department of Chemical Engineering, Loughborough University, Loughborough, LEICS, LE11 3TU, UK.

e-mail: G.Shama@,Lboro.ac.uk

Tel: + 441509222514

Fax: +44 1509223923

Keywords: Alginate Immobilization, Dunaliella parva, Glycerol, Photobioreactor

\begin{abstract}
A novel configuration of photobioreactor is described in which filaments of alginate containing immobilized cells of a leaky mutant of Dunaliella parva are wound round a central light well which is located within a glass outer chamber so that a liquid medium is caused to flow in the annular space between the outside chamber and the alginate filaments. Glycerol production by D. parva was maintained for 700 hours, and the highest concentration of glycerol attained was approximately $12 \mathrm{mg} \mathrm{l}^{-1}$.
\end{abstract}




\section{Introduction}

In his review of the commercial cultivation of micro-algae, Borowitzka (1999) suggests that for certain products future advances will be dependent on the development of efficient closed systems for the cultivation of single algal species. Where the desired end product is not the algal biomass itself there are advantages to employing immobilization. These include greater control over primary and secondary metabolism, continuous operation independent of low algal growth rates and retention of the algae within the bioreactor. Robinson et al. (1986) have pointed out that the use of immobilized algae goes back to the first use of percolating filters for the treatment of sewage and other liquid wastes, a process which is over one hundred years old. The current interest in immobilization of algae is much more recent and includes applications for secondary metabolite production (Leach et al., 1998), energy generation in the form of hydrogen gas (Hahn et al., 2007) and uptake of heavy metals from wastewater streams (Mata et al., 2009). Whilst there have been developments in bioreactors for the cultivation of free living or planktonic algae including bubble columns (Zhi and Rorrer, 1996) and various airlift designs (Merchuk et al., 2000), this has not been paralleled by comparable developments in novel configurations for immobilized algae. Where the latter are used it is often in the form of small beads, typically $3 \mathrm{~mm}$ in diameter, and more often than not alginate forms the immobilization matrix.

In this work a novel configuration of bioreactor for use with immobilized phototrophs is proposed. The particular application described here is for the production of the glycerol by Dunaliella parva. 


\section{Materials and Methods}

Photobioreactor

This is formed of two parts. The first of which is a cylindrical glass tube which acts both as a support for the immobilised organisms, and as a central light well. The upper part of this component consists of a ground glass cone (Diameter: $0.06 \mathrm{~m}$ ) fused to a glass tube (Length: $0.215 \mathrm{~m}$; Outer Diameter: $0.053 \mathrm{~m}$ ) sealed only at one end. Three solid glass rings (Outer Diameter $0.033 \mathrm{~m}$ ) were fused to the outside of the tube at $0.03,0.09$ and $0.15 \mathrm{~m}$ from the base of the tube. The function of these rings was to prevent the spirally wound alginate fibres from slipping down the tube. The second part of the photobioreactor comprised a glass outer casing (Length: $0.2 \mathrm{~m}$; Outer Diameter: 0.025 m) fitted with a ground glass socket at its upper end. A liquid medium inlet was located $0.18 \mathrm{~m}$ from the bottom of the casing and a medium exit was provided at the base of the casing. When the two parts of the photobioreactor was assembled together an annular channel was formed in which liquid medium was made to flow past the immobilised organisms (Figure 1a). 


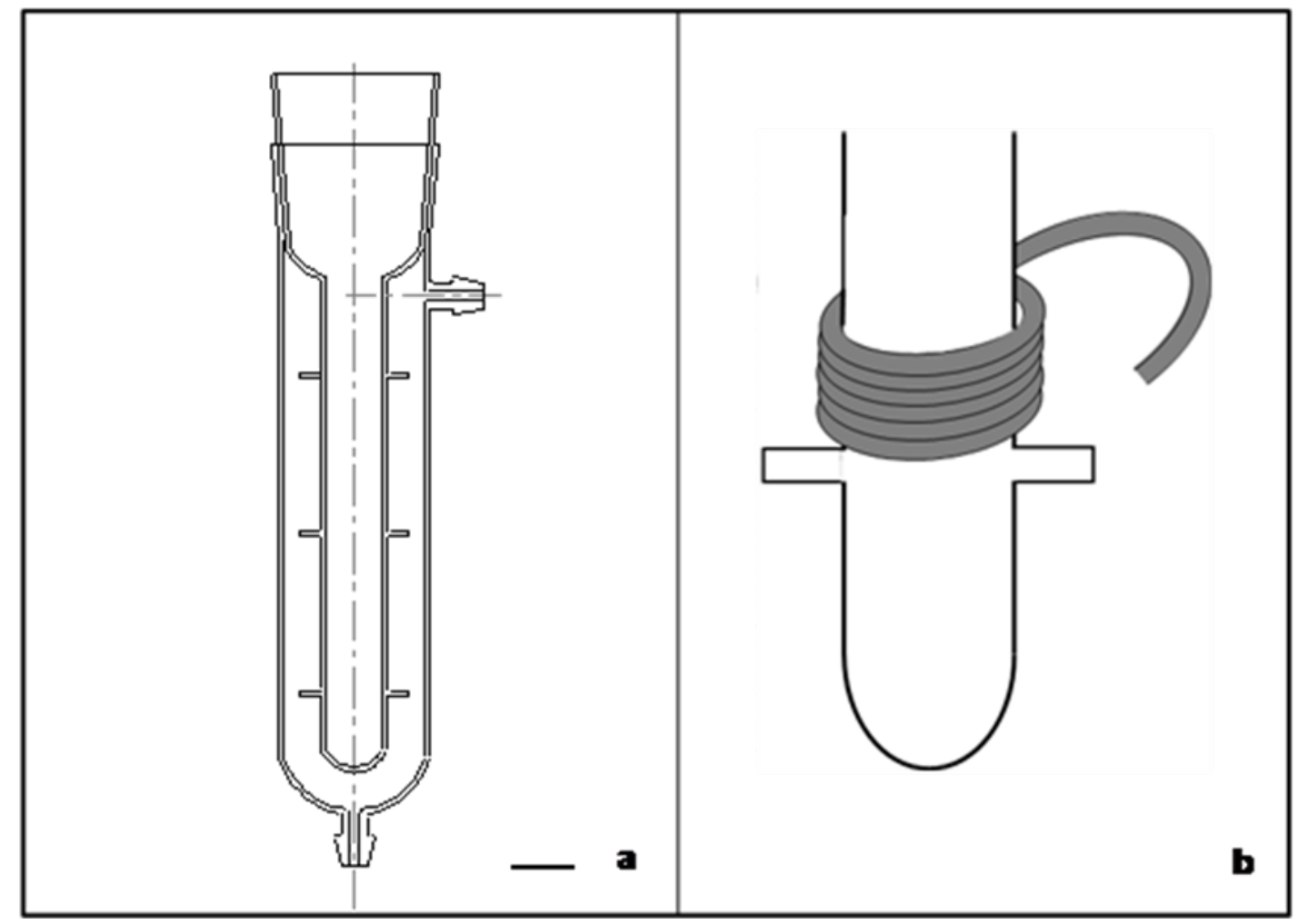

Figure 1.a) Photobioreactor. Bar represents $2.5 \mathrm{~cm}$. b) Method of winding alginate fibre around central light well

Liquid medium was conveyed to the photobioreactor from a glass reactor vessel (Capacity $0.5 \mathrm{l}$ ) via silicone tubing by means of a peristaltic pump (Series 501, Watson Marlow, Falmouth, Cornwall). The medium flowrate was fixed at $0.01 \mathrm{lh}^{-1}$. The medium exited the photobioreactor at its base and was returned to the reactor vessel. The vessel was equipped with a sintered glass gas sparger which was supplied either with air or a mixture of $\mathrm{CO}_{2}$ and nitrogen via rotameters. The mixed gases were passed to a Dreschel bottle partially filled with water to pre-saturate them before they entered the reaction vessel so as to prevent evaporative losses. The reactor also contained a dip tube through which liquid samples could be withdrawn by means of a syringe into glass bijou bottles. The reactor vessel was suspended in a water bath which was maintained at a temperature of $18^{\circ} \mathrm{C}$ by means of a chiller unit (Cole-Parmer Instrument Co., Hanwell, London- not shown) and which was controlled by a custom-made temperature controller. Light was 
provided by means of an $8 \mathrm{~W}$ source (Philips UK Ltd., Guildford, Surrey) placed inside the light well and by two external light sources (each $15 \mathrm{~W}$, Philips) on each side of the photobioreactor at a distance from it of $0.2 \mathrm{~m}$. The photobioreactor and the light sources were enclosed within an elliptical reflector made from highly reflective anodised aluminium of major diameter $0.8 \mathrm{~m}$ in order to maximise light utilisation.

Algal Culture, Growth Conditions and Harvesting

A leaky mutant of Dunaliella parva CCAP 19/9 was kindly supplied by Dr D J Gilmour of the Department of Molecular Biology and Biotechnology, University of Sheffield. This organism was grown in a salts growth medium as previously described by Hard and Gilmour (1991).

In order to prepare cells for immobilization eight $250 \mathrm{ml}$ Erlenemyer flasks each containing $100 \mathrm{ml}$ of salts medium were inoculated and incubated under illumination from a single tubular source ( $40 \mathrm{~W}$, Philips) at $20^{\circ} \mathrm{C}$ for $10 \mathrm{~d}$. The cultures were pooled and then centrifuged at $5000 \mathrm{~g}$ for 10 minutes at $4{ }^{\circ} \mathrm{C}$. Cell concentration was determined by measuring chlorophyll concentration after extraction with $80 \%(\mathrm{v} / \mathrm{v})$ acetone and reading absorptions at 645 and $663 \mathrm{~nm}$ (McKinney, 1941) after having first obtained a calibration for cell number versus chlorophyll content. The final cell concentration was $1.75 \times 10^{7} \mathrm{ml}^{-1}$.

Immobilization of Algae

The algal pellet obtained as described above was re-suspended into $125 \mathrm{ml}$ of a solution of $2.0 \%(\mathrm{w} / \mathrm{v})$ sodium alginate (Sigma-Aldrich, Dorset). The suspension was then 
extruded by means of a syringe into a chilled $0.25 \mathrm{M}$ solution of calcium chloride. The extruded fibres were held at $4{ }^{\circ} \mathrm{C}$ for $24 \mathrm{~h}$ in order to harden before being used. The fibres were then wound round the central light well in between the glass support rings (see Figure 1b) and then held in place by means of a 'thimble' of nylon gauze fashioned from a piece of hosiery (10 denier).

Determination of Glycerol

This was performed by the method described by Hard and Gilmour (1941).

\section{Results and Discussion}

Glycerol production was maintained for a period of time exceeding $700 \mathrm{~h}$ (Figure 2). Over this period the filaments were not displaced from their position surrounding the central light well nor were they subject to obvious signs of damage. For the first $200 \mathrm{~h}$ of the experiment the sparger had been supplied with air at a flowrate of $72 \mathrm{l} \mathrm{h}^{-1}$ which was equivalent to approximately $28.8 \mathrm{ml} \mathrm{CO}_{2} \mathrm{~h}^{-1}$. Moreover, only the light source located in the central light well was illuminated. Thereafter a $\mathrm{N}_{2}-\mathrm{CO}_{2}$ gas mixture was used, and a $\mathrm{CO}_{2}$ input of $90 \mathrm{ml} \mathrm{h}^{-1}$ was selected. Although the concentration of glycerol had been increasing before this adjustment, the rate of glycerol production following the addition of pure $\mathrm{CO}_{2}$ increased at a greater rate. At 315 hours the $\mathrm{CO}_{2}$ input rate was increased 2.5 fold. This led to an initial increase in glycerol concentration followed by a rather steep decrease. At $543 \mathrm{~h}$ the $\mathrm{CO}_{2}$ input rate was reduced to its previous value and the two external light sources were switched on. These changes led to a modest increase in the rate of glycerol production. 


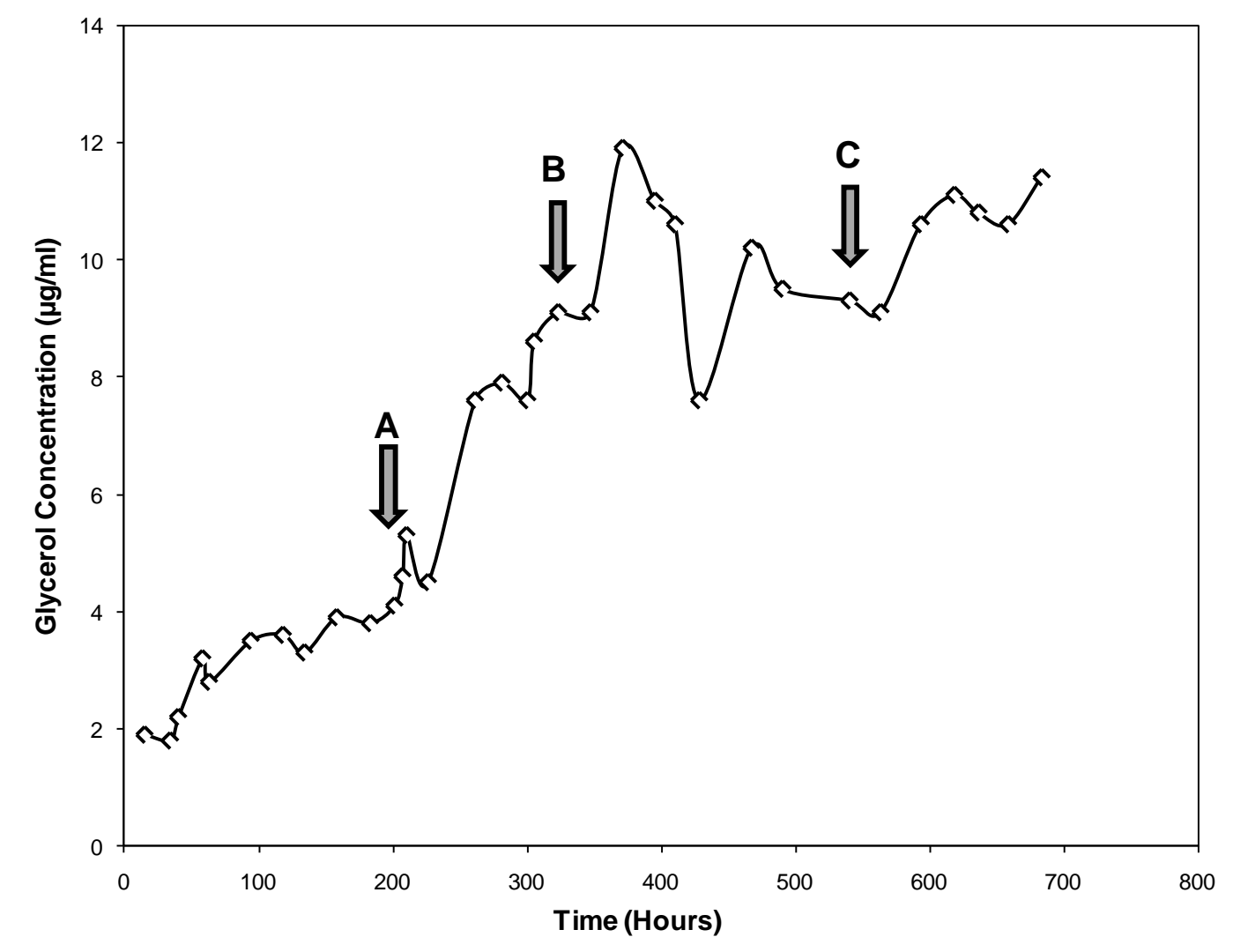

Figure 2 Glycerol Production over Time by Immobilized Dunaliella parva

A Gas supply changed from air to $\mathrm{CO}_{2} / \mathrm{N}_{2} ; \mathrm{CO}_{2}$ flowrate $28 \mathrm{ml} \mathrm{h}^{-1}$

$\mathrm{B} \mathrm{CO}_{2}$ flowrate increased to $90 \mathrm{ml} \mathrm{h}^{-1}$

C $\mathrm{CO}_{2}$ flowrate reduced to $28 \mathrm{ml} \mathrm{h}^{-1}$, additional light sources used

The highest concentration of glycerol achieved was $12 \mathrm{mg} \mathrm{l}^{-1}$. This was somewhat low compared to the values obtained by previous workers e.g. Grizeau and Navarro (1986) obtained values of approximately $5 \mathrm{~g}^{-1}$ using a high yielding strain of $D$. tertiolecta. The reduced concentration obtained in this work was to some extent the result of the relatively high working bioreactor volume of approximately 0.81 . This was partly dictated by the need to maintain constant temperature using the temperature controller employed here; a less responsive system may have enabled stable temperature operation with lower liquid volumes. Moreover, precise comparison with the results obtained by Hard and Gilmour (1991) using the same strain of $D$. parva could not be obtained because these 
workers expressed their yields in terms of $\mu$ moles of glycerol $/ \mathrm{mg}$ chlorophyll. At the same concentration of $\mathrm{NaCl}$ employed here their yield obtained using planktonic cells was approximately $40 \mu$ moles glycerol/mg chlorophyll. In this work the chlorophyll concentration was only measured prior to immobilization, and a slight loss of colour was noted over the course of the experiment. Notwithstanding, based on initial chlorophyll concentration the highest value obtained here was $2.6 \mu$ moles/mg chlorophyll. Whilst this is almost certainly an underestimate of the true yield, it should be noted that only limited attempts were made (as described above) to optimise conditions for glycerol production.

Whilst the solid glass rings attached to the exterior of the central light well successfully supported the alginate fibres, it was still found necessary to retain the fibres by means of a nylon mesh. The type described in Materials and Methods proved suitable for this purpose but was found to result in the adherence of gas bubbles - presumably oxygen during operation. Their accumulation might have inhibited metabolism, but it was found that gentle tapping of the photobioreactor on a daily basis was sufficient to displace them. These attached bubbles could also have been induced to detach by increasing the liquid velocity of the liquid flowing past. Alternatively, a more open mesh could have been used to retain the alginate filaments in place and might have enabled the bubbles to disengage more readily. The requirement for the mesh was to some extent dictated to by the fact that the method described here of manually extruding the alginate fibre inevitably led to unsteady pressure being exerted on the syringe resulting in some kinking of the fibre. This made it slightly more difficult to wind the fibre around the light well tightly and to attain efficient coverage of the exterior of the light well. The use of an automatic syringe pump would obviate this problem and result in straighter fibres. 
The photoreactor described here proved suitable for the production of a metabolite by immobilized algae. In particular, light utilization was maximized in such a way that can not be achieved with packed bed reactors (Robinson et al. 1986). Fluidised bed bioreactors employing immobilised organisms are subject to inter-particle shear forces, and whilst these can prove useful in sloughing off excess biomass growth (Sokol and Halfani, 1999) in applications such as that described here the effect of such forces is undesirable as it would lead to cell losses. In addition, growth of immobilized algae will eventually destroy the alginate immobilization matrix, this is a general problem that Mallick (2002) has pointed out. Processes involving immobilized algae can be therefore only of a short duration, unless growth of the biomass is somehow suppressed completely while continuing the production of the extracellular metabolite. Whilst the operation of the photobioreactor was demonstrated here with reference to $D$. parva and glycerol, its features would readily lend itself to many other applications centred on phototrophs.

\section{References}

Borowitzka M (1999) Commercial production of microalgae: ponds tanks, tubes and fermenters. J Biotech 70:313-321

Hahn JJ, Ghirardi ML, Jacoby, WA (2007) Immobilized algal cells used for hydrogen production. Biochem Eng J 37:75-79

Hard BC, Gilmour, DJ (1991) A mutant of Dunaliella parva CCAP19/9 leaking large amounts of glycerol into the medium. J Appl Phycol 3:367-372 
Grizeau D, Navarro JM (1986) Glycerol production by Dunaliella tertiolecta immobilized with Ca-alginate beads. Biotech Lett 8:261-264

Leach G, Oliveira, G, Morais, R (1998) Production of a carotenoid-rich product by alginate entrapment and fluid-bed drying of Dunaliella salina. J Sci Food Agric 76:298-302

Mallick J (2002) Biotechnological potential of immobilized algae for wastewater N, P and metal removal: A review. BioMetals 15: 377-390

Mata YN, Blazquez ML, Ballester A, Gonzalez F, Munoz JA (2009) Biosorption of cadmium, lead and copper with calcium alginate xerogels and immobilized Fucus vesiculosus. J Hazard Mat 163:555-562

McKinney G (1941) Absorption of light by chlorophyll. J Biol Chem 140:315-322

Merchuk JC, Gluz M, Mukmenev I (2000) Comparison of photobioreactors for cultivation of the red microalga Porphyridium sp. J Chem Tech Biotech 75:1119-1126

Robinson PK, Mak, AL, Trevan, MD (1986) Immobilized algae: a review. Proc Biochem 21:122-127

Sokol W, Halfani MR (1999) Hydrodynamics of a gas-liquid-solid fluidised bed bioreactor with a low density biomass support. Biochem Eng J 3:185-192

Zhi C, GL Rorrer (1996) Photolithotrophic cultivation of Laminaria saccharina gametophyte cells in a bubble-column bioreactor. Enz Micro Tech 18:291-299 